\title{
Patterns of Tooth Size Variability in the Dentition of Primates
}

PHILIP D. GINGERICH AND MARGARET J. SCHOENINGER

Museum of Paleontology and Department of Anthropology, The University of Michigan, Ann Arbor, Michigan 48109

KEY WORDS Primate dentition . Dental variability . Dental fields

\begin{abstract}
Published data on tooth size in 48 species of non-human primates have been analyzed to determine patterns of variability in the primate dentition. Average coefficients of variation calculated for all species, with males and females combined, are greatest for teeth in the canine region. Incisors tend to be somewhat less variable, and cheek teeth are the least variable. Removing the effect of sexual dimorphism, by pooling coefficients of variation calculated for males and females separately, reduces canine variability but does not alter the basic pattern. Ontogenetic development and position in functional fields have been advanced to explain patterns of variability in the dentition, but neither of these appears to correlate well with patterns documented here. We tentatively suggest another explanation. Variability is inversely proportional to occlusal complexity of the teeth. This suggests that occlusal complexity places an important constraint on relative variability within the dentition. Even when the intensity of natural selection is equal at all tooth positions, teeth with complex occlusal patterns must still be less variable than those with simple occlusion in order to function equally well. Hence variability itself cannot be used to estimate the relative intensity of selection. Low variability of the central cheek teeth $\left(\mathbf{M}_{1}^{1}\right.$ and $\left.\mathbf{M}_{2}^{2}\right)$ makes them uniquely important for estimating body size in small samples, and for distinguishing closely related species in the fossil record.
\end{abstract}

The existence of variation is a prerequisite for evolution by natural selection. No description of an organ, organism, or population is complete without characterizing both its typical characteristics and the variations or deviations from typical. Books have been written about variation and variability in mammals (e.g., Berry and Southern, '70; Yablakov, '74; see also Long, '69), but relatively little is yet known about the variability of many anatomical systems. The study of variation and variability is time consuming because measurements of large samples are required for adequate characterization. In recent years tooth size has been studied in many primates. Hooijer ('48) described the variability of the orangutan dentition in one of the earliest quantitative studies based on a large sample size. Additional studies have since appeared that document dental variability in other spe- cies of living primates (Schuman and Brace, '55; Freedman, '57; Olson and Miller, '58; Hooijer, '60; Swindler et al., '63; Biggerstaff, '66; Zingeser, '67; Pilbeam, '69; Leutenegger, '71; Wolpoff, '71; Gingerich, '74; Johanson, '74; Swindler, '76; Gingerich and Ryan, '79). Most of these papers describe dental variability in anthropoid primates, and relatively little has been reported of variability in prosimians.

In this study we have attempted to achieve something of a synthesis by analyzing variability across a broad range of primates. The analysis shows that there is a definite pattern to dental variability in primates. This pattern is important for understanding functional fields in the dentition. Knowledge of the pattern is also very useful for interpreting the systematic relationships and the adaptations of fossil primates. 


\section{MATERIALS AND METHODS}

The most complete compilation of statistics on tooth size in primates is the recent book by Swindler (76). Swindler lists means and standard deviations of tooth length and width for males and females of 56 species of primates. We used all of Swindler's data for which the sample size at a given tooth position in males and in females is equal to or greater than five, i.e., a minimum of five males and five females were included in any sample used in our analysis. A total sample size of ten is far below optimum for characterizing variability in an individual species, but it is probably adequate for use in statistical summaries of variability across many species. Most species included were represented by many more than five individuals of each sex. This arbitrary sample size criterion reduced the number of species from Swindler's tables that we included in the analysis to 44. We added data for four species of Indriidae from Gingerich and Ryan ('79) to increase the representation of prosimians. The final 48 species included representatives of Tupaiidae (2 sp), Lemuridae (1 sp)), Indriidae (4 sp.), Lorisidae (4 sp.), Tarsiidae (1 sp. composite), Callitrichidae (1 sp.), Cebidae (7 sp.), Cercopithecoidae (22 sp.), Hylobatidae (2 sp.), and Pongidae (4 sp.).

Swindler ('76), and Gingerich and Ryan (79) give statistical summaries separately at each tooth position for the males and females of each species. Data for males and females were combined in two ways: (1) We first combined the means and standard deviations using the following appropriately weighted formulae (Gingerich, '74: p. 897):

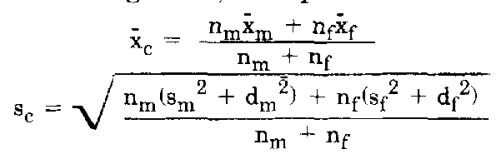

where:

$\mathrm{n}_{\mathrm{m}}$ and $\mathrm{n}_{\mathrm{f}}$ are the number of males and females respectively

$\bar{x}_{m}, \bar{x}_{f}$ and $\dot{x}_{c}$ are the male, female, and combined means

$s_{m}, s_{f}$ and $s_{c}$ are the male, fernale and com-

bined standard deviations

$$
\begin{aligned}
& d_{m}=\bar{x}_{c}-\bar{x}_{m} \\
& d_{f}=\bar{x}_{c}-\bar{x}_{f}
\end{aligned}
$$

The coefficient of variation of the species sample is then:

$$
\mathrm{V}=100 \mathrm{~s}_{\mathrm{c}} / \mathrm{x}_{\mathrm{c}}
$$

This is an "across-sex" coefficient including the variability contributed by sexual dimorphism (where present) as well as inherent variability at each tooth position for each species. (2) To factor out any contribution of sexual dimorphism, we also computed coefficients of variation separately for males and for females, using the standard formulae:

$$
\begin{aligned}
& v_{m}=100 s_{m} / \bar{x}_{m} \\
& v_{f}=100 s_{f} / \bar{x}_{\mathrm{f}}
\end{aligned}
$$

A weighted mean coefficient of variation was calculated from these separate male and female coefficients, using the formula:

$$
\mathrm{V}^{*}=\frac{\mathrm{n}_{\mathrm{m}} \mathrm{V}_{\mathrm{m}}+\mathrm{n}_{\mathrm{f}} \mathrm{V}_{\mathrm{f}}}{\mathrm{n}_{\mathrm{m}}+\mathrm{n}_{\mathrm{f}}}
$$

The result is a "within-sex" coefficient of variation at each tooth position for each primate species. $V$ is the normal coefficient of variation for a species, and $V^{*}$ is the coefficient with sex related variability removed. Finally, the mean and the range for each of the two coefficients of variation, $\mathrm{V}$ and $\mathrm{V}^{*}$, were computed at each tooth position for all species represented. The results are presented in table 1 and illustrated graphically in figures 1 and 2.

A note should be added here concerning the statistical summaries published by Swindler (76). Most of his original measurements were made on plaster dental casts made from alginate impressions of the original primate specimens. These were carefully made, and a series of measurements on casts were tested against measurements of the original specimens to demonstrate that the two are directly comparable (Swindler et al., '63). It is thus unlikely that Swindler's ('76) measurements of means are significantly biased. However, these extra steps involved in going from the original specimen to the final measurement are bound to increase, at least slightly, the variance in the final result. Similarly, many of Swindler's samples are geographically heterogeneous, which might also increase the variance over that found in more homogeneous samples. Neither a slight systematic bias in means nor a slight systematic bias in variances should affect the patterns of variability shown here, but the absolute values of the various coefficients of variation appear to be slightly higher than expected and this could well be a result of measuring casts and/or using geographically heterogeneous samples. Many of the authors listed in the beginning of the article have published statistical summaries based on measurements of original speci- 
TABLE 1

Coefficients of variation of tooth length ( $L$ ) and width (W) for $N$ species of primates

\begin{tabular}{|c|c|c|c|c|c|c|c|c|}
\hline \multirow{3}{*}{$\begin{array}{l}\text { Tooth } \\
\text { position }\end{array}$} & & \multicolumn{4}{|c|}{ V "Across-Sex" (fig. 1) } & \multicolumn{3}{|c|}{$\dot{V} *$ "Within-Sex" (fig. 2) } \\
\hline & & \multirow[b]{2}{*}{$\mathbf{N}$} & \multicolumn{2}{|c|}{ Range } & \multirow[b]{2}{*}{ Mean } & \multicolumn{2}{|c|}{ Range } & \multirow[b]{2}{*}{ Mear } \\
\hline & & & Min & Max & & Min & $\operatorname{Max}$ & \\
\hline \multicolumn{9}{|c|}{ Upper dentition } \\
\hline \multirow[t]{2}{*}{$I^{1}$} & $\mathbf{L}$ & 34 & 5.0 & 18.2 & 9.4 & 4.6 & 17.4 & 8.9 \\
\hline & W & 34 & 3.1 & 23.7 & 9.7 & 3.0 & 22.6 & 9.1 \\
\hline \multirow[t]{2}{*}{$\mathbf{1}^{2}$} & $\mathrm{~L}$ & 34 & 6.6 & 22.6 & 10.2 & 6.2 & 21.3 & 9.7 \\
\hline & $W$ & 34 & 5.7 & 27.2 & 10.0 & 5.4 & 25.9 & 9.3 \\
\hline \multirow[t]{2}{*}{$\mathrm{C}^{1}$} & $\mathrm{~L}$ & 36 & 4.5 & 31.8 & 15.8 & 4.2 & 16.4 & 9.5 \\
\hline & W & 36 & 4.6 & 26.0 & 14.4 & 4.1 & 17.7 & 9.8 \\
\hline \multirow[t]{2}{*}{$\mathbf{P}^{2}$} & $\mathrm{~L}$ & 13 & 6.1 & 13.6 & 9.9 & 5.3 & 12.4 & 9.0 \\
\hline & $\bar{W}$ & 13 & 5.1 & 14.3 & 8.7 & 4.8 & 14.0 & 8.3 \\
\hline \multirow[t]{2}{*}{$\mathrm{P}^{3}$} & L. & 43 & 4.4 & 15.5 & 8.6 & 4.4 & 15.2 & 8.0 \\
\hline & $\mathbf{W}$ & 43 & 4.0 & 16.3 & 8.6 & 3.8 & 15.6 & 8.1 \\
\hline \multirow[t]{2}{*}{$\mathrm{P}^{4}$} & $\mathrm{~L}$ & 43 & 4.0 & 17.2 & 7.6 & 3.3 & 16.8 & 7.2 \\
\hline & $\bar{W}$ & 43 & 4.1 & 26.4 & 7.9 & 4.0 & 20.6 & 7.1 \\
\hline \multirow[t]{2}{*}{$\mathbf{M}^{1}$} & $\mathrm{~L}$ & 44 & 3.5 & 10.3 & 6.1 & 3.4 & 10.1 & 5.7 \\
\hline & $\bar{W}$ & 44 & 3.7 & 16.0 & 7.1 & 3.3 & 15.6 & 6.5 \\
\hline \multirow[t]{2}{*}{$\mathbf{M}^{2}$} & $\mathrm{~L}$ & 45 & 4.3 & 9.9 & 6.3 & 3.8 & 9.8 & 5.8 \\
\hline & $\mathrm{W}$ & 45 & 3.9 & 13.6 & 7.0 & 3.7 & 12.9 & 6.3 \\
\hline \multirow[t]{2}{*}{$\mathrm{M}^{3}$} & $\mathrm{~L}$ & 37 & 4.4 & 19.7 & 9.0 & 4.0 & 19.2 & 8.4 \\
\hline & $\bar{W}$ & 37 & 4.5 & 11.6 & 7.8 & 4.0 & 11.3 & 7.1 \\
\hline \multicolumn{9}{|c|}{ Lower dentition } \\
\hline \multirow[t]{2}{*}{$I_{1}$} & $\mathrm{~L}$ & 33 & 4.7 & 34.7 & 10.4 & 4.5 & 32.0 & 9.6 \\
\hline & $\mathbf{W}$ & 33 & 5.4 & 17.4 & 9.5 & 5.2 & 16.9 & 8.8 \\
\hline \multirow[t]{2}{*}{$\mathbf{I}_{2}$} & $\mathrm{~L}$ & 34 & 4.6 & 28.4 & 10.0 & 4.5 & 28.3 & 9.3 \\
\hline & $\bar{W}$ & 34 & 4.3 & 21.5 & 9.3 & 3.1 & 21.2 & 8.5 \\
\hline \multirow[t]{2}{*}{$\mathrm{C}_{1}$} & $\mathrm{~L}$ & 27 & 5.8 & 30.6 & 16.6 & 5.5 & 18.6 & 11.6 \\
\hline & $W$ & 27 & 4.1 & 46.3 & 17.4 & 3.9 & 37.1 & 11.4 \\
\hline \multirow[t]{2}{*}{$P_{a}$} & $\mathrm{~L}$ & 11 & 7.0 & 15.7 & 11.8 & 5.1 & 15.4 & 9.7 \\
\hline & $\mathrm{W}$ & 11 & 5.8 & 12.8 & 10.5 & 5.4 & 12.7 & 9.1 \\
\hline \multirow[t]{2}{*}{$\mathbf{P}_{3}$} & $\mathrm{~L}$ & 40 & 4.8 & 38.9 & 14.9 & 4.4 & 21.4 & 10.3 \\
\hline & $\mathrm{W}$ & 40 & 5.4 & 24.7 & 11.0 & 5.1 & 19.2 & 9.5 \\
\hline $\mathrm{P}_{4}$ & $\mathrm{~L}$ & 42 & 4.3 & 16.4 & 7.7 & 4.2 & 15.9 & 7.2 \\
\hline & 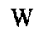 & 42 & 4.5 & 19.2 & 8.7 & 3.9 & 18.9 & 8.1 \\
\hline $\mathbf{M}_{t}$ & $\mathrm{~L}$ & 44 & 3.9 & 10.4 & 6.0 & 2.6 & 10.2 & 5.5 \\
\hline & $\bar{W}$ & 44 & 4.0 & 19.2 & 7.1 & 4.0 & 18.8 & 6.6 \\
\hline $\mathrm{M}_{2}$ & $\mathrm{~L}$ & 45 & 3.4 & 9.2 & 5.8 & 3.4 & 9.1 & 5.3 \\
\hline & $\mathbf{W}$ & 45 & 3.6 & 15.8 & 7.1 & 3.1 & 15.6 & 6.6 \\
\hline $\mathbf{M}_{3}$ & $\mathrm{~L}$ & 37 & 3.5 & 14.3 & 7.5 & 3.5 & 13.6 & 6.9 \\
\hline & $\mathrm{W}$ & 37 & 3.9 & 12.3 & 7.2 & 3.2 & 12.0 & 6.7 \\
\hline
\end{tabular}

mens in geographically homogeneous sample populations, and these should be consulted when values of the coefficients of variation in a single species are needed.

\section{VARIABILITY IN TOOTH SIZE}

Average coefficients of variation at different tooth positions across a broad range of primates are listed in table 1. Calculating the coefficients of variation for each species with males and females combined (V) yields an extreme range of values from a minimum of 3.1 to a maximum of 46.3 . The average values of $\mathrm{V}$ at different tooth positions from 5.8 for $\mathrm{M}_{2}$ length to 17.4 for lower canine width. There is a definite pattern to the average values calculated for combined samples of males and females. This pattern is illustrated by the solid circles in figure 1 . The canine region of the dentition is consistently the most variable, with average coefficients of variation of about 15.0 for the canines and for the most anterior lower premolars occluding with the upper canines. The incisor region has average coefficients of variation of about 10.0. The remainder of the premolar and molar dentition has average values ranging from about 8.0 at the anterior or posterior ends of the series to a low of about 6.0 or 7.0 in the middle of the series ( $\mathrm{M}_{1}^{\frac{1}{1}}$ and $\left.\mathrm{M}_{2}^{\frac{2}{2}}\right)$. Three functional fields can 
be identified in the primate dentition: an incisor field, a canine field, and a cheek tooth field (Butler, '39; and others). Each of these functional fields has a characteristic level of variability, with the canine field being most variable, cheek tooth field being least variable, and the incisor field being intermediate in variability.

The functional field with the greatest variability, the canine field, is known to be highly dimorphic in most anthropoid primates. We anticipated that sexual dimorphism might adequately explain the high variability observed in canine size. This was tested by calculating coefficients of variation within each sex, and then computing a weighted average of these $\left(\mathrm{V}^{*}\right)$ at each tooth position for each species (table 1). Variability calculated in this way is consistently slightly less than that calculated for mixed male and female samples because the original samples are more homogeneous (i.e., all of one sex). As expected, the very high average coefficients of variation in the canine functional field were reduced considerably when the effect of sex was removed.

The average coefficients of variation, $V^{*}$, at different tooth positions calculated by the "within-sex" method are shown graphically with solid circles in figure 2 . The solid line segments connecting solid circles show the pattern of variability with the contribution of sexual dimorphism removed. The dashed line segments in figure 2 represent the patterns of variability shown by solid line segments in figure 1 , which include the contribution of sexual dimorphism. The difference between "across-sex" means and "within-sex" means in table 1 is a measure of the contribution of sexual dimorphism to dental variability in primates. The area between the solid connecting segments and the dashed line segments in figure 2 represents the same contribution graphically. As expected, variability of the ca. nine teeth is most affected by sexual dimorphism. Surprisingly, however, even after the effect of sex differences is factored out, teeth in the canine functional field are still slightly more variable than those in the incisor or cheek tooth fields. The relatively higher variability of canine teeth cannot be explained solely as a result of sexual dimorphism.

\section{DISCUSSION}

The results of this study are interesting for several reasons. As outlined above, the rela- tively high variability of teeth in the canine functional field $\left(\mathrm{C}_{1}^{1}\right.$ and $\mathrm{P}_{2}$ or $\left.\mathrm{P}_{3}\right)$ cannot be adequately explained by sexual dimorphism alone. Sexual dimorphism contributes the greatest component to canine variability, but when this effect is removed the canine field still has slightly higher variability than neighboring fields.

In a previous study, Gingerich ('74) advance two hypotheses to explain patterns of size variability in the mammalian dentition: (1) sequences of ontogenetic development-late developing teeth might be more variable due to increasing hormonal differentiation associated with sexual dimorphism, and (2) variability may follow the pattern of functional fields in the dentition-teeth in the center of incisor, canine, and cheek tooth fields being less variable because they are a more critical component of an animal's adaptation than teeth at the periphery of fields. A subsequent study of patterns of dental variability in large samples of four species of Indriidae indicated that the first of these hypotheses is not viable. The second molars in indriids were consistently less variable than first molars even though they develop and erupt later (Gingerich and Ryan, '79). We have also calculated rank correlations of dental eruption sequence with variability in the upper and lower dentition of all four species of Indriidae. These correlations do not even approach statistical significance, and in fact tend to be slightly negative.

The second hypothesis, that variability follows the pattern of functional fields in the dentition, appeared to be substantiated by patterns in Indriidae (Gingerich and Ryan, 79), where the upper canine with caniniform lower $\mathbf{P}_{3}$ and the central cheek teeth $\left(\mathbf{M}_{2}^{2}\right)$ are less variable than surrounding teeth. This appeared plausibly to be a reflection of underlying canine and cheek tooth functional fields. However, our results presented here do not corroborate the functional field hypothesis as an explanation of variability patterns, and the patterns in Indriidae can as well be explained by the new hypothesis outlined below. Figure

Fig. 1 Patterns of variability in the upper and lower dentition of primates, with the "across-sex" coefficient of variation $\mathrm{V}$ calculated as outlined in the text. Solid circles are means and vertical bars are ranges of $\mathrm{V}$ at each tooth position for the number of species shown at the base of each vertical bar. Solid line segments connect means, showing a pattern of high canine variability and low molar size variability. Data from table 1 . 

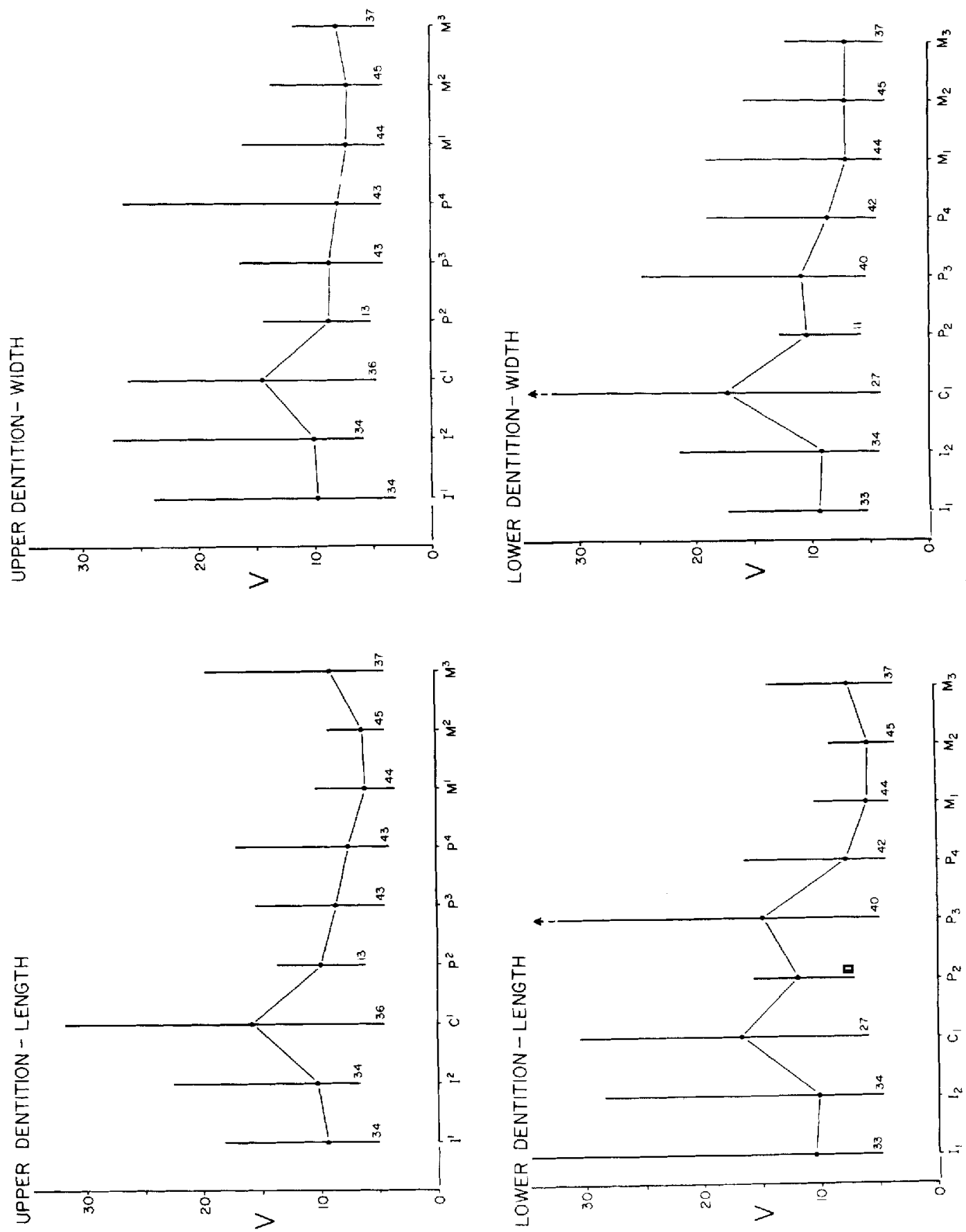
2 shows that the patterns of variability in the cheek teeth of primates conform to the expected field effect, but there is no reduction in canine variability corresponding to a canine functional field. The upper central incisors are less variable than their lateral counterparts, as would be expected for a single incisor field extending across the midline and incorporating all of the incisors, but in the lower dentition the reverse is the case: the central incisors are more variable than the lateral incisors. As a result, neither of the previously proposed hypotheses appears to explain the observed patterns of dental variability.

Another explanation for the observed patterns is suggested by figure 2 , and we here tentatively advance a new hypothesis that variability is inversely proportional to occlusal complexity. Canine teeth are usually the simplest in the dentition in terms of both their form and their occlusion. Upper canines in most primates have a simple, pointed crown that occludes with a similarly shaped lower canine and/or anterior lower premolar. This occlusion involves only one curved edge contacting and moving past another similarly curved edge. Any slight malocclusion is automatically corrected by the wear of one edge against the other. Incisor teeth in many primates (including those best represented in our data set) are spatulate in shape, and occlude with the straight edge of a lower incisor matching the straight edge of an upper. Incisors are constrained both by neighboring teeth and by their edge-to-edge occlusion. Cheek teeth have the most complex crown morphology, with numerous precisely positioned cusps on the lower premolars and molars occluding with their counterparts in the upper dentition. These cusps are usually positioned in such a way that the same teeth can be used differently in several occlusal phases and functions. Because of this complex occlusion, less variability can be tolerated in the cheek tooth region if these teeth are to function properly.

Patterns of variability like those shown in figure 2 are sometimes explained as a reflection of the differential selective value of different dental elements, with low variability indicating highest selective value (e.g., Gingerich and Ryan, '79). Exceptionally high variability is usually associated with characters that are not rigidly integrated and/or with non-functional or vestigial characters (Simp- son, ' 53 ; pp. 75, 148). Applying this interpretation to patterns of size variability in the primate dentition, cheek teeth would appear to have the highest selective value and canine teeth the lowest selective value. However, all of the teeth are parts of one dentition, and an alternative interpretation is possible. Natural selection acts on individuals, and the survival of an individual primate in the wild requires that all components of its dentition occlude at some minimal functional level. Teeth with simple occlusion (canines) can be relatively more variable in size and form than teeth with complex occlusion (cheek teeth) and still occlude at the same functional level. The relative variability of teeth at different positions is not a measure of the relative selective value or intensity of selection. The data presented here suggest that dental variability is inversely proportional to occlusal complexity. Even if the intensity of selection is equal at all tooth positions, teeth with complex occlusal patterns must be less variable than teeth with simple occlusion in order to function equally well. Variability within the dentition is probably more a measure of occlusal complexity than of the relative intensity of selection.

The three hypotheses that have been advanced to explain patterns of dental variability in primates are not mutually exclusive. There may be an ontogenetic contribution to variability, and there may well be some field effect, but neither of these by itself is sufficient to explain the observed patterns. The occlusal complexity hypothesis proposed here does account for patterns of variability published to date, but its generality remains to be tested by detailed studies of variability in individual primate species and other mammalian groups.

Two final points need to be discussed. The relatively low variability of central cheek teeth ( $\mathrm{M}_{1}^{\frac{1}{1}}$ and $\left.\mathrm{M}_{2}^{2}\right)$ makes them the most useful for estimating the average body size of a primate species from a sample of dental remains such as one typically finds in the fossil record.

Fig. 2 Patterns of variability in the upper and lower dentition of primates, with the "within-sex" coefficient of variation $V^{*}$ calculated as outlined in the text. Means, ranges, and sample sizes are shown for each tooth position as in figure 1. Dashed lines show pattern of variability in $\mathrm{V}$ (from fig. 1) compared to that of $\mathrm{V}^{*}$ shown here with solid line segments. Note reduction in canine variability when the effect of sexual dimorphism is removed. Note also that variability of teeth in the canine field still remains relatively high. Data from table 1. 

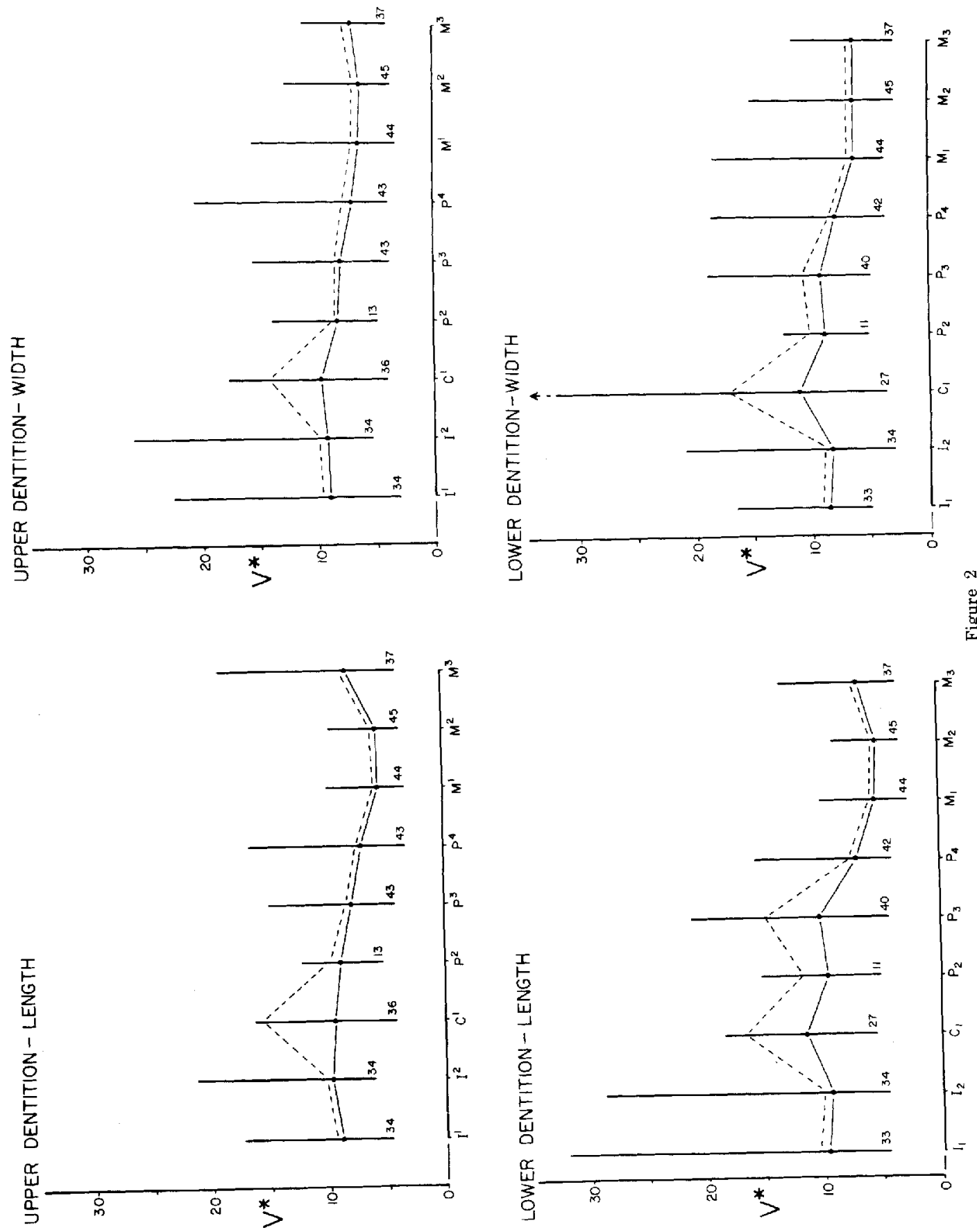
Tooth size at other positions is also very highly correlated with body size, but the fact that tooth size is more variable at the other positions necessarily reduces the correlation slightly. It is possible that canine tooth size is more highly correlated with individual body size than is the size of a central cheek tooth (especially in dimorphic species), but for a general estimate of the average body size of a species calculations based on $\mathrm{M}_{1}^{1}$ or $\mathrm{M}_{2}^{2}$ size are likely to give the best results. Kay ('75) has shown that $\mathrm{M}_{2}$ length is highly correlated with body weight in primates $(r=0.96)$, and first or second molar length can be used effectively to estimate body size in fossil primates (Gingerich, '77; Fleagle, '78).

Gingerich ('74) suggested that the size of $\mathrm{M}_{1}$ tends to be the least variable of the lower cheek teeth across a range of mammals. Further study of additional species has in some cases supported this (Gingerich and Winkler, '79), while in other species it is clear that $M_{2}$ is the least variable (Gingerich and Ryan, '79). It appears that in different species the position of lowest size variability is centered over different cheek teeth, depending on the length and conformation of the cheek tooth field. Our study of dental variability across a broad range of primates supports the general hypothesis that $\mathrm{M}_{1}^{1}$ or $\mathrm{M}_{2}^{2}$ will be the least variable. These are thus the best teeth on which to base size diagnoses of very closely related species. Siegel ('78) and others have questioned basing diagnoses of fossil primate species on tooth size, suggesting that bimodality of tooth size within a species may make interpretations ambiguous. Some primate species have statistically significant differences in molar size between males and females, but this is never of a sufficient magnitude to make the distributions of molar size bimodal. Canine size is often bimodal in primate species, but the size of the first or second molars never is (cf. Pilbeam and Zwell, '72: figs. 3, 4).

\section{CONCLUSIONS}

The publications listed in the introduction and our analysis presented here indicate that dental variation and patterns of variability are becoming relatively well known in primates. Variability itself cannot be used to estimate the relative intensity of selection in the primate dentition because variability also appears to be related to occlusal complexity. The central cheek teeth are the least variable teeth in the primate dentition, and they are thus very useful for predicting the average body size of species and for size diagnoses of closely related and morphologically similar species.

\section{ACKNOWLEDGMENTS}

This work was supported in part by Research Grant DEB 77-13465 from the $\mathrm{Na}$ tional Science Foundation. We thank Mrs. Anita Benson for typing the manuscript. Critical comments by an anonymous reviewer greatly improved the discussion.

\section{LITERATURE CITED}

Berry, R. J., and H. N. Southern, eds. 1970 Variation in Mammalian Populations. Symp. Zool. Soc. Lond., 26: 1-403.

Biggerstaff, R. H. 1966 Metric and taxonomic variations in the dentitions of two Asian cercopithecoid species: Macaca mulatta and Macaca speciosa. Am. J. Phys. Anthrop., 24: 231-238.

Butler, P. M. 1939 Studies of the mammalian dentition-differentiation of the post-canine dentition. Proc. Zool. Soc. Lond., 109: 1-36.

Fleagle, J. G. 1978 Size distributions of living and fossil primate faunas. Paleobiology, 4: 67-76.

Freedman, L. 1957 The fossil Cercopithecoidea of South Africa. Ann. Transv. Mus., 23: 121-262.

Gingerich, P. D. 1974 Size variability of the teeth in living mammals and the diagnosis of closely related sympatric fossil species. J. Paleont., 48: 895-903.

_ 1977 Correlation of tooth size and body size in living hominoid primates, with a note on relative brain size in Aegyptopithecus and Proconsul. Am. J. Phys. Anthrop., 47: $395-398$.

Gingerich, P. D., and A. S. Ryan 1979 Dental and cranial variation in living Indriidae. Primates, 20: 141-159.

Gingerich, P. D., and D. A. Winkler 1979 Patterns of variation and correlation in the dentition of the red fox, Vulpes vulpes. J. Mammal., 60: in press.

Hooijer, D. A. 1948 Prehistoric teeth of man and of the orang-utan from central Sumatra, with notes on the fossil orang-utan from Java and southern China. Zool Meded. (Leiden), 29; 175-284.

1960 Quaternary gibbons from the Malay Ar chipelago. Zool. Verh. (Leiden), 46: 1-41.

Johanson, D. C. 1974 Some metric aspects of the permanent and decidnous dentition of the pygmy chimpanzee (Pan paniscus). Am. J. Phys. Anthrop., 41: 39.48.

Kay, R. F. 1975 The functional adaptations of primate molar teeth. Am. J. Phys. Anthrop., 43; 195-216.

Leutenegger, W. 1971 Metric variability of the postcanine dentition in colobus monkeys. Am. J. Phys. Anthrop., 35: 91-100.

Long, C. A. 1969 An analysis of patterns of variation in some representative mammalia. Part. II. Studies on the nature and correlation of measures of variation. Misc Publ. University of Kansas Mus. Nat. Hist., 51: 289-302.

Olson, E. C., and R. L. Miller 1958 Morphological Integration. University of Chicago Press, Chicago.

Pilbeam, D. R. 1969 Tertiary Pongidae of East Africa: evolutionary relationships and taxonomy. Bull. Peabody Mus. Nat. Hist., Yale University, 31: 1-185.

Pilbeam, D. R., and M. Zwell 1972 The single species hypothesis, sexual dimorphism, and variability in early hominids. Yearbook Phys. Anthrop., 16: 69-79. 
Schuman, E. L., and C. L. Brace 1955 Metric and morphologic variations in the dentition of the Liberian chimpanzee. Human Biol., 26: 239-268.

Simpson, G. G. 1953 The Major Features of Evolution. Columbia University Press, New York.

Siegel, M. I. 1978 Dentofacial relationships in sexually dimorphic populations. In: Recent Advances in Primatology. D. J. Chivers and K. A. Joysey, eds. Academic Press, New York, Vol. 3, pp. 73.75.

Swindler, D. R. 1976 Dentition of Living Primates. Academic Press, New York.
Swindler, D. R., J. A. Gavan and W. M. Turner 1963 Molar tooth size variability in African monkeys. Human Biol., 35: 104-122.

Wolpoff, M. H. 1971 Metric trends in hominid dental evolution. Studies Anthrop., Case Western Reserve University, $2: 1.244$.

Yablakov, A. V. 1974 Variability of Mammals. Amerind Publ. Co., New Delhi.

Zingeser, M. R. 1967 Odontometric characteristics of the howler monkey (Alouatta caraya). J. Dent. Res., 46: 975-978. 